\title{
A Pilot Study on Screening of BRCA1 Mutations (185delAG, 1294del40) in Nepalese Breast Cancer Patients
}

\author{
Bibek Bhatta ${ }^{1 *}$, Roshina Thapa ${ }^{1}$, Sanjay Shahi ${ }^{1}$, Yogesh Bhatta ${ }^{4}$, Dipendra Raj \\ Pandeya $^{2}$, Bal Hari Poudel ${ }^{3 *}$
}

\begin{abstract}
Background: Breast cancer is the second most common malignancy among Nepalese women, accounting for $60 \%$ of the total cancer cases in females. Women diagnosed with germline mutations in BRCA1 like 185delAG, 1294del40 develop breast and/or ovarian cancer with a lifelong likelihood of up to $85 \%$ whereas presence of a mutation increases the risk for mutations to occur in other genes. The major objective of this study was to find the prevalence of these mutations in Nepalese cancer patients. Materials and Methods: This prospective study was carried out at two cancer hospitals in the Kathmandu valley over a period of 11 months. Irrespective of age group and stage of canceran appropriate amount of blood was withdrawn from 50 breast cancer patients and 20 controls. DNA was extracted manually and subjected to PCR using primers for 185delAG and $1294 d e l 40$ mutations. PCR products were then digested with restriction enzyme (DdeII) followed by electrophoresis. Results: Prevalence of 185delAG in reference breast cancer patients was found to be 4/50 (8\%) but no 1294 del40 was apparent. Conclusions: Several mutations occurring in different exons of BRCA1 as well as mutations in other genes like BRCA2, for example, should also be taken in account.
\end{abstract}

Keywords: Breast cances - susceptibility genes - BRCA1 - 185delAG - mutation - Nepal

Asian Pac J Cancer Prev, 17 (4), 1829-1832

\section{Introduction}

Since the localization (the long arm (q) of chromosome 17 (17q12-21))(Miki et al., 1994) and isolation of the breast cancer susceptibility gene BRCA1, various studies have revealed that highly penetrant mutations in BRCA1 constitute very high risk of breast cancer (Peto et al., 1999; Papelard et al., 2000; Stegel et al., 2011). BRCA1 is a large gene with 22 coding exons encoding a $220 \mathrm{kD}$ protein that functions in maintaining genomic integrity and in transcriptional regulation (Belogianni et al., 2004). Frameshift and nonsense mutations are the predominant germ line mutations of BRCA1 gene, which causes either loss or mutation of the remaining allele leading to total inactiveness of BRCA1 gene in the infected cell(ShattuckEidens et al., 1995). Thus engendered truncated proteins may lack the biochemical functions when equated to its prototype, may be non-functional due to aberrant sub cellular localization or physically absent due to rapid degradation (Miki et al., 1994; Kainu et al., 1996).

Breast cancer is the leading cancer in Asian females and its incidence is further uphill(Kim and Choi, 2013). The global burden of breast cancer is expected to cross 2 million by the year 2030, with growing proportions from developing countries(Jemal et al., 2011). In Nepal it is the 2 nd most common cancer in women $(7.2 \%$ of all malignancy) (Piya and Acharya, 2012). It is high in perimenopausal women (41 to $50 \mathrm{yrs}$ ) i.e. the risk of breast cancer increases exponentially up to the age of menopause, and then the rate of increase in the risk slows significantly (Smigal, 2006). In addition, BRCA1 mutations also appear to predispose to a range of other cancer types (prostate, pancreatic, colon cancer etc.) (Capalbo et al., 2006). In 2012, the total number of breast cancer cases in Nepal was 1716, Age Specific Incidence Rate (ASIR) was 13.7/100000 and Age Specific Mortality rate (ASMR) was 2.7/100000 respectively(Ghoncheh et al., 2015).

BRCA1 mutation analysis is a method of genetic testing that evaluates individual risk status for breast or ovarian cancer. It may be considered after studying family history, providing pre-test genetic counselling. Genetic testing predicts the likelihood of developing cancer and does not mean that the cancer will or will not occur. There are 1536 distinct mutations, polymorphisms and variants in BRCA1 and although less than 5\% of total breast cancer patients have mutations in the BRCA1 gene, but the carrier have a $60 \%-80 \%$ probability of developing breast cancer (Saxena et al., 2006; Kim and Choi, 2013). Screening of

${ }^{I}$ Department of Clinical Microbiology, Nobel College, ${ }^{2}$ Department of Clinical Biochemistry, Nepalese Army Institute of Health Science, College of Medicine, Kathmandu, ${ }^{3}$ Central Department of Biotechnology, Tribhuvan University, Kirtipur, ${ }^{4}$ Mahakali Zonal Hospital, Mahendranagar, Nepal*For correspondence: bek.bhatta@gmail.com 
these germline mutations serves as a critical diagnostic tool to identify the cancer in its inchoate state so as to constrict the carcinomal invasion and its complications. Although for genetic testing it's advantageous to know founder and/or recurrent mutation but since little have been studied about the mutation screening and profiling in Nepal, so this study was carried out to gauge the contribution of BRCA1 mutation (185delAG, 1294del40) to the incidence of breast cancer in reference Nepalese population or patients.

\section{Materials and Methods}

Prospective study was carried out at a cancer hospital in the Kathmandu valley for a period of 11 months. Preceding the study, approval was obtained from the institutional research ethical review board. Irrespective of age group and stages of cancer appropriate amount of blood was withdrawn from 50 breast cancer positive patients and 20 controls (normal womens). DNA was extracted manually, subjected to PCR using primers for 185delAG and 1294del40 mutations. PCR products were then digested with restriction enzyme (DdeII) followed by $4 \%$ Gel Electrophoresis for detection of former 185delAG mutation. Finally bands were visualized over UV-transilluminator.

\section{Sample Collection And Storage}

After obtaining written consent form from each individual, $5 \mathrm{ml}$ peripheral blood sample was collected into EDTA vials and stored at $4^{\circ} \mathrm{C}$ until further processing.

\section{DNA extraction}

DNA extraction was carried out using "Lahiri and Nurnberger" protocol(Lahiri and Nurnberger, 1991). The quality of the DNA was checked by $0.8 \%$ agarose gel electrophoresis. The quantity of the DNA was measured spectrophotometrically.

\section{Table 1. Description of Primers Used}

\begin{tabular}{cccc}
\hline \multirow{2}{*}{ Mutations } & \multirow{2}{*}{ Exon } & \multicolumn{2}{c}{ Primers set used } \\
\cline { 3 - 4 } & & Foreward Primer & Reverse Primer \\
\hline \multirow{2}{*}{ 185DelAG } & 2 & 5'-AAA ATG AAG & 5'-CTG ACT \\
& & TAT AAA CC-3' & GGA CAT T-3 \\
& & 5'-GAA TAA GCA & 5'-CTC TAC \\
1294Del40 & \multirow{2}{*}{11} & GAA ACT GCC & TGA TTT GGA \\
& & ATG C-3' & GTG AAC TC-3' \\
\hline
\end{tabular}

Table 2. PCR Conditions

$95{ }^{\circ} \mathrm{C}$ for 10 minute followed by 35 cycles of denaturation, annealing and extension depending on mutation primer sets

\begin{tabular}{cccc}
\multicolumn{4}{c}{ used. } \\
\hline Mutation & Denaturation & Annealing & Extension \\
\hline 185 DelAG & $30 \mathrm{~s}$ at $94^{\circ} \mathrm{C}$ & $30 \mathrm{~s}$ at $52^{\circ} \mathrm{C}$ & $1.0 \mathrm{~min}$ at $72^{\circ} \mathrm{C}$ \\
$1294 \mathrm{Del} 40$ & $30 \mathrm{~s}$ at $94^{\circ} \mathrm{C}$ & $30 \mathrm{~s}$ at $54^{\circ} \mathrm{C}$ & $1.0 \mathrm{~min}$ at $72^{\circ} \mathrm{C}$ \\
R1443X & $30 \mathrm{~s}$ at $95^{\circ} \mathrm{C}$ & $30 \mathrm{~s}$ at $56^{\circ} \mathrm{C}$ & $1.0 \mathrm{~min}$ at $72^{\circ} \mathrm{C}$ \\
\hline
\end{tabular}

The reaction is ended with $10 \mathrm{~min}$ incubation at $72{ }^{\circ} \mathrm{C}$. PCR Product put at $4{ }^{\circ} \mathrm{C}$ on Hold.

\section{PCR amplification}

For amplification Mastermix was prepared with 7.5ul PCR Buffer, 6ul dNTPs and 0.9ul Taq Polymerase. 4.8ul of this mastermix was taken and in it 1ul Template DNA, 1ul Foreward and 1ul Reverse Primer (Specific to the Mutation) was added followed by $17.2 \mathrm{ul}$ of Nuclease Free Water to obtain final volume of $25 \mathrm{ul}$ in PCR tube. The PCR Primer sets and the condition for amplification for the different mutation detection were varied and is shown below Table1 and Table 2 respectively:

\section{Restriction digestion and visualization}

For 185delAG the PCR products were digested with $1 \mathrm{U}$ of restriction enzymes and were detected by resolving over $4 \%$ agarose gel containing Ethidium Bromide (EtBr). For 1294del40 mutation, 500ml of Running Buffer was prepared50ml of 5X TAE buffer was mixed with distilled water to make the final volume $500 \mathrm{ml} .50 \mathrm{ml}$ of that buffer was mixed with $1 \mathrm{gm}$ of Agarose, mixed well and boiled till clear (2\% agarose gel). $40 \mu \mathrm{l}$ of Ethidium bromide was mixed with the molten gel in a flask and poured onto the Gel-cast.

Electrophoresis was performed at $80 \mathrm{~V}-50 \mathrm{mAmp}$ for 45 minutes. The resolved bands were visualized over an UV-trans-illuminator. Summary of restriction digestion enzyme and its restricted product can be seen in Table 3:

\section{Results}

The mean age of onset of cancer in our study was found to be 42.59 . For 185 delAG mutation, out of 50 samples tested, 4 samples ( $8 \%$ ) showed undigested band in the range of $176 \mathrm{bp}$ meaning positive for this mutation, while the other 75 samples showed digested bands, with one on the range of $150 \mathrm{bp}$ and the other on the range of $26 \mathrm{bp}$ as shown in the Figure 1:

For 1294del40 mutation, the PCR products after electrophoresis and visualization under UV showed

Table 3. Restriction Enzymes Used and their Products

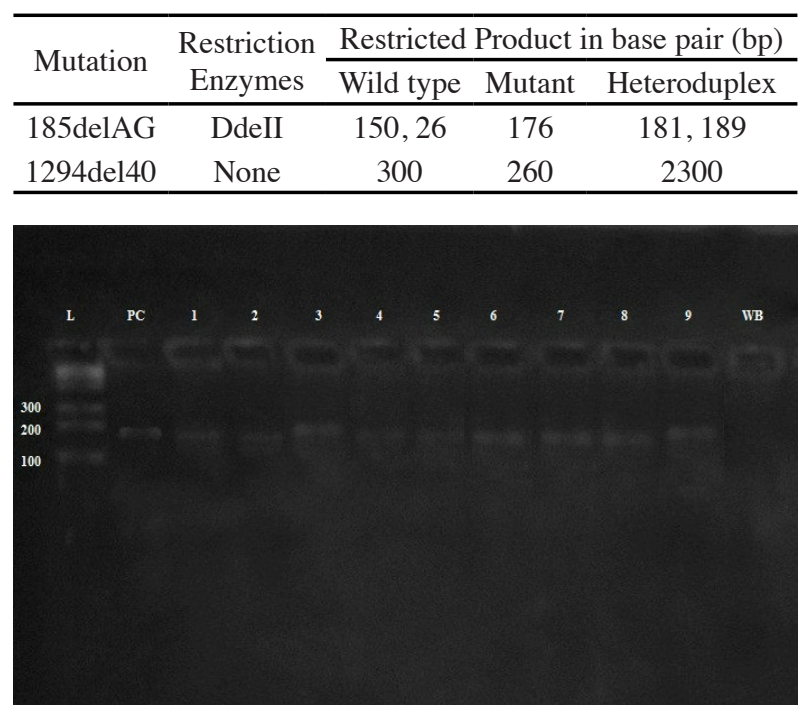

Figure 1. L : Ladder, PC :Positice control, WB : WaterBlank, Sample 1-2;4-8 show digested band(wild type) Sample 3\&9 show undigested band(mutated) 
distinct band of amplified DNA sequence. The band sizes were found to be $300 \mathrm{bp}$ that is of wild type and no samples showed two bands that would appear for mutated type at 260bp (mutated).

\section{Discussion}

The mean age of onset of cancer in our study was found to be 42.59 which was slightly lower than the age (46.5 \pm 12.8 : Range 25 to 80 years) revealed by other study in Nepal (Singh and Sayami, 2009). A study done on different ethinicities showed that the mean age at the time of testing was $50 \pm 11.9$ years among European women, whereas the mean age was $45.2 \pm 10.9$ years for women of African descent, and 47.1 12.5 years for women of Asian descent(Hall et al., 2009). Although we tested for different founder mutations, our study only revealed the presence of $185 \mathrm{delAG}$ mutation in our reference population. $8 \%$ of our study population showed 185 delAG mutation which was relatively lower than the result shown by a study done at India, which revealed an alarming prevalence of 16.3\%(Karami and Mehdipour, 2013). Another study in India found $185 \mathrm{delAG}$ mutation in 4 familial breast cancer patients with an age of diagnosis of $35,37,40$ and 50 years (Rashid et al., 2006). In a similar study done in eastern India there was found to be no prevalence of $185 \mathrm{delAG}$ mutation(Chakraborty et al., 2014). Hansa et al found the presence of $185 \mathrm{del} A \mathrm{~A}$ mutation in his study which was conducted in north east India(Hansa et al., 2012).The mutation 185delAG has been coined as the "Ashkenazi Mutation" because it was predominantly detected among Ashkenazi Jews having attained a $1 \%$ carrier frequency within the population since origin of the ancestral mutation(Struewing et al., 1995).Its prevalence have shown a diversity among different parts of world. A study done in Korea didn't showed the prevalence of 185delAG mutation as well as 5382insC mutation in BRCA1(Ahn et al., 2004). Among non-Jewish Americans of Spanish ancestry from the San Luis Valley,185delAG mutation have been reported to be present in high frequency of $31.6 \%$ but contrastingly it has been found at a very low prevalence rate (1.13-5.9\%) among white Americans, the Spanish from Spain, Polish, Iranian, Pakistani and Turkish women(Vaidyanathan et al., 2009).

A frequency of nearly $1 \%$ among the general population has been reported for a 40-bp deletion, 1294del 40, within large exon 11 of the BRCA1 gene, which leads to the translation termination(Walker and Rapley, 2005). 1294 del40 mutation sought to be important in causation of early onset of breast cancer in women. Hence, the detection of this particular mutation could give an insight into the relative risk of breast cancer in pre-symptomatic relatives of the breast cancer patients, especially in their first degree relatives in our region where this mutation has not been tested/ researched yet.

The variation in our study may be due to small reference population that we included in our study. In addition it may also be possible that the mutation may be occouring in other exons of BRCA1 or even in other genes like BRCA2, p53 etc which thus initiated an importance to screen those mutation as well.
In conclusion, The assumption behind screening high risk women for genetic cancer susceptibility is that, in those individuals affected, the cancers anticipated can be prevented or their negative health impact reduced by early diagnosis. However, it would be interesting to investigate the carrier frequency of these mutations among diversity (religious/ethnic/geographical groups) of Nepalese population with a larger sample size to further understand its prevalence and origin.

\section{Acknowledgement}

We would like to acknowledge UGC (University Grant Commission, Bhaktapur) for their support as well as all the people who directly and indirectly aided our study.

\section{References}

Ahn SH, Hwang UK, Kwak BS, et al (2004). Prevalence of BRCA1 and BRCA2 mutations in Korean breast cancer patients. J Korean Med Sci, 19, 269-74.

Belogianni I, Apessos A, Mihalatos M, et al (2004). Characterization of a novel large deletion and single point mutations in the BRCA1 gene in a Greek cohort of families with suspected hereditary breast cancer. BMC Cancer, $\mathbf{4}, 61$.

Capalbo C, Ricevuto E, Vestri A, et al (2006). BRCA1 and BRCA2 genetic testing in Italian breast and/or ovarian cancer families: mutation spectrum and prevalence and analysis of mutation prediction models. Ann Oncol, 17, 34-40.

Chakraborty A, Banerjee D, Basak J, et al (2014). Absence of 185delAG and 6174delT mutations among breast cancer patients of eastern India. Asian Pac J Cancer Preve, 16, 7929-33.

Ghoncheh M, Mohammadian-Hafshejani A, Salehiniya H (2015). Incidence and mortality of breast cancer and their relationship to development in Asia. Asian Pac J Cancer Prev, 16, 6081-7.

Hall MJ, Reid JE, Burbidge LA, et al (2009). BRCA1 and BRCA2 mutations in women of different ethnicities undergoing testing for hereditary breast-ovarian cancer. Cancer, 115, 2222-33.

Hansa J, Kannan R, Ghosh SK (2012). Screening of 185DelAG, 1014DelGT and 3889DelAG BRCA1 mutations in breast cancer patients from North-East India. Asian Pac J Cancer Prev, 13, 5871-4.

Jemal A, Bray F, Center MM, et al (2011). Global cancer statistics. CA Cancer J Clin, 61, 69-90.

Kainu T, Kononen J, Johansson O, et al (1996). Detection of germline BRCA1 mutations in breast cancer patients by quantitative messenger RNA in situ hybridization. Cancer Res, 56, 2912-5.

Karami F, Mehdipour P (2013). A Comprehensive focus on global spectrum of BRCA1 and BRCA2 mutations in breast cancer. BioMed Research Int, 2013, 21.

Kim H, Choi DH (2013). Distribution of BRCA1 and BRCA2 mutations in asian patients with breast cancer. J Breast Cancer, 16, 357-65.

Lahiri DK, Nurnberger JI (1991). A rapid non-enzymatic method for the preparation of HMW DNA from blood for RFLP studies. Nucleic Acids Res, 19, 5444.

Miki Y, Swensen J, Shattuck-Eidens D, et al (1994). A strong candidate for the breast and ovarian cancer susceptibility gene BRCA1. Science, 266, 66-71.

Papelard H, de Bock GH, van Eijk R, et al (2000). Prevalence of BRCA1 in a hospital-based population of Dutch breast 
cancer patients. Br J Cancer, 83, 719-24.

Peto J, Collins N, Barfoot R, et al (1999). Prevalence of BRCA1 and BRCA2 gene mutations in patients with early-onset breast cancer. J National Cancer Institute, 91, 943-9.

Piya MK, Acharya SC (2012). Oncology in Nepal. South Asian J Cancer, 1, 5-8.

Rashid MU, Zaidi A, Torres D, et al (2006). Prevalence of BRCA1 and BRCA2 mutations in Pakistani breast and ovarian cancer patients. Int J Cancer, 119, 2832-9.

Saxena S, Chakraborty A, Kaushal M, et al (2006). Contribution of germline BRCA1 and BRCA2 sequence alterations to breast cancer in Northern India. BMC Med Genet, 7, 75.

Shattuck-Eidens D, McClure M, Simard J, et al (1995). A collaborative survey of 80 mutations in the BRCA1 breast and ovarian cancer susceptibility gene. Implications for presymptomatic testing and screening. Jama, 273, 535-41.

Singh YP, Sayami P (2009). Management of breast cancer in Nepal. JNMA J Nepal Med Assoc, 48, 252-7.

Smigal C JA, Ward E, Cokkinides V, Smith R, Howe HL (2006). Trends in breast cancer by race and ethnicity: update 2006. J Clin Diagn Res, 56, 106-30.

Stegel V, Krajc M, Zgajnar J, et al (2011). The occurrence of germline BRCA1 and BRCA2 sequence alterations in Slovenian population. BMC Med Genet, 12, 9 .

Struewing JP, Abeliovich D, Peretz T, et al (1995). The carrier frequency of the BRCA1 185delAG mutation is approximately 1 percent in Ashkenazi Jewish individuals. Nat Genet, 11, 198-200.

Vaidyanathan K, Lakhotia S, Ravishankar H, et al (2009). BRCA1 and BRCA2 germline mutation analysis among Indian women from south India: identification of four novel mutations and high-frequency occurrence of $185 \mathrm{delAG}$ mutation. J Biosciences, 34, 415-22.

Walker JM, Rapley R (2005). Medical Biomethods Handbook, Springer. 